\title{
Damping Low Frequency Oscillations via FACTS- POD Controllers Tuned by Bees Algorithm
}

\author{
Nurul Aziah Arzeha*, Mohd Wazir Mustafa and Rasyidah Mohamad Idris \\ School of Electrical Engineering, Faculty of Engineering, Universiti Teknologi Malaysia, 81310 UTM, Johor, Malaysia. \\ *Corresponding author: aziah.arzeha@fkegraduate.utm.my, Tel: 6013-2220739
}

\begin{abstract}
Power systems are often subject to low frequency electro-mechanical oscillations resulting from electrical disturbances and consequence of the development of interconnection of large power system. Flexible Alternating Current Transmission System (FACTS) devices with Power Oscillation Damping (POD) as the supplemet controller has been recent research interest in damping the oscillation. Bees Algorithm (BA) is applied to optimized the parameters of the FACTS-POD controller. The main objective of optimization is to improve the system stability by moving the electro-mechanical eigenvalues on the s-plane to the left as far as possible. The controller is tested on a 3-machine 9-bus system and simulated in PSAT in MATLAB environment. The system is disturbed by increasing $10 \%$ mechanical input to Generator 2 and second disturbance is the system experiencing a three-phase fault. The performance of the system with the FACTS-POD controller is observed in terms of position of electromechanical eigenvalues on s-plane and damping responses of power oscillations where both terms shows significant improvement as compared to the system without FACTS-POD controller.
\end{abstract}

Keywords: Bees algorithm, eigenvalues analysis, FACTS controllers, power oscillation damping.

(C) 2018 Penerbit UTM Press. All rights reserved

Article History: received 30 August 2017; accepted 2 August 2018; published 29 August 2018.

\section{INTRODUCTION}

Low freqency oscillation has been occurred spontaneously at very low frequency ranging from 0.2 $3.0 \mathrm{~Hz}$ due to development of interconnection of large electric power system $[1,2,3]$. The oscillations could build up gradually following not just a major disturbance but also a small sudden change such as a moderate amount of load tripping, a sudden addition of a large load, tripping of a minor transmission line, etc [4,5]. They could continue for a long time and keep growing in terms of magnitude, hence threatening system security, damages the efficient operation of the power system and affecting small signal stability or even causing system seperation if not well damp.

Generally, the oscillations are classified into two types. Local oscillations range from $0.5-2.0 \mathrm{~Hz}$ depend on the machine and system parameters and loading conditions $[4,5,6]$. The oscillations may occur when there is a disturbance in an area with closely coupled generators where the machine rotors swing against each other and with respect to the rest of the system. The other case where the oscillation of a single generator or a group of generators against the rest of the system may also causing the occurrence of local oscillatios. The other type is interarea oscillations range from $0.1-0.5 \mathrm{~Hz}$ where it usually occur in large interconnected systems, the oscillations $[3,4,5]$. The oscillations may appear following a major disturbance in the tie-line flow as generators in one area (swinging more or less in unison) swing against generators in other areas (again, swinging more or less in unison).

Power system stabilizer (PSS) has been used to damp out the low frequency oscillatios, however it may not provide sufficient damping for inter-area oscillations in certain conditions $[6,7,8,9]$. Thus, Flexible alternating current transmission system (FACTS) devices has become an alternative solution in such condition. The fast progress in power electronics field in recent years has added the option for improvement of power system stability by utilizing the flexible and rapid control of flexible alternating current transmission system (FACTS) $[10,11,12]$. There has been extensive studies being done on potential of supplementary functions of FACTS devices that is damping low-frequency oscillation and enhance power system small-signal stability [3]. Recently, designing the FACTS devices with power oscillation damping (POD) controller to enhance the small-signal stability and damp out power system oscillation controller has spark the interest of researchers $[4,5,6,11]$.

This paper presents the effectiveness of FACTS-POD controllers in enhancing small-signal stability and damping out low frequency oscillation. The FACTS devices include TCSC, SVC, SSSC, STATCOM and UPFC. The parameters of FACTS-POD will be tuned and optimized by employing Bees Algorithm (BA) so that the electromechanical eigenvalues is positioned to the left as far as possible. Then, the controllers will be tested on WSCC 3-machines, 9-bus system in MATLAB via 
PSAT. Two cases will be done, first is increasing $10 \%$ of mechanical input (Pm) at Generator 2 and the second case is the occurrance of 3-phase fault at bus 7 of the system. Each cases will be simulated with each type of FACTSPOD controllers individually and the results will be compared to the system that have not installed with any controller.

\subsection{State space representation of power system}

Power system stability can be analyzed more conveniently by using the linearizing system. The system is linearized about the initial point and both local and inter-area oscillations can be analyzed to give useful information regarding the system small-disturbance performance. Hence, any instability occurrence was easier to identify and appropriate design of control system can be done to overcome the problem.

Small-signal analysis can be done on power system once the linearized model is obtained. The whole power system can be represented by one linear vector matrix where it usually done through state-space approach. The vector matrix contains the dynamic response information of the whole set of system variables, thus proper analysis on the eigenvalues of the matrix can gives useful information about the system performance. The system performance could be affected by a change of control parameters in particular machine and will be reflected in the eigenvalues. Hence, interpretation of the eigenvalues technique allowing identification of system unstability, causes and probable solution of the problem. A power system can be represented by the following sets of differential and algebraic equations $[5,13,14]$ :

$$
\begin{aligned}
& \dot{x}=f(x, z, u) \\
& 0=g(x, z, u) \\
& y=h(x, z, u)
\end{aligned}
$$

After linearization the above can be expressed as;

$$
\begin{aligned}
& \Delta \dot{x}=\frac{\partial f}{\partial x} \Delta x+\frac{\partial f}{\partial z} \Delta z+\frac{\partial f}{\partial u} \Delta u \\
& 0=\frac{\partial g}{\partial x} \Delta x+\frac{\partial g}{\partial z} \Delta z+\frac{\partial g}{\partial u} \Delta u \\
& \Delta \dot{x}=\frac{\partial h}{\partial x} \Delta x+\frac{\partial h}{\partial z} \Delta z+\frac{\partial h}{\partial u} \Delta u
\end{aligned}
$$

Elimination of the vector algebraic variable $\Delta z$ from equation (4) and (5), gives

$$
\begin{aligned}
& \Delta \dot{x}=A \Delta x+B \Delta u \\
& \Delta y=C \Delta x+D \Delta u
\end{aligned}
$$

where $A, B, C, D$ are the matrix of partial derivatives in (4) to (6) evaluated at initial points. As in PSAT, the initial conditions are obtained after simulating the power flow of the system.

Interpretation from the solution of the vector differential equation $\dot{\mathbf{x}}=\mathbf{A x}$ can give useful information on the system performance. A real eigenvalues shows that the sistem is stable. As it corresponds to a non-oscillatory term, a positive real value give aperiodic stability while negative value gives a decaying mode. The larger its magnitude, the faster the decay [15]. Meanwhile a complex pair conjugate eigenvalues corresponds to ocsillatory term. Consists of two terms, imaginary part equal to frequency of oscillation and the other is the real part that if it is negative the oscillation will decays and if it is positive the oscillation will increase in amplitude [15].

When the eigenvalues show the unstable performance, the system can be stabilized by utilizing a feedback. The input $\mathbf{u}(t)$ is usually chosen to be function of the state variables, so that $\mathbf{u}=-\mathbf{h x}$, where $\mathbf{h}$ is the feedback matrix. The state equation (7) then becomes:

$$
\dot{\mathbf{x}}=\mathbf{A x}-\mathbf{B h} \mathbf{x}=[\mathbf{A}-\mathbf{B h}] \mathbf{x}=\mathbf{A} 1 \mathbf{x}
$$

Suitable selection of variable $\mathbf{h}$ could improve the system stability. The POD controller replacing the feedback control system as shown in Figure $1[5,6,14,16]$.

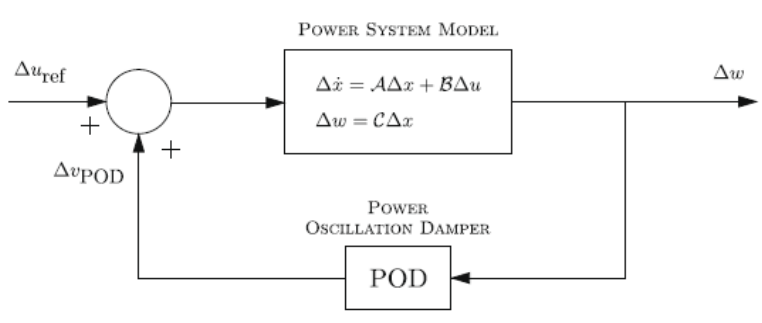

Figure 1. General feedback control system

\section{POWER OSCILLATION DAMPER}

The structure of the POD controller is similar to the classical power system stabilizer (PSS), as shown in Figure 1 [16]. The controller consists of three main components. A stabilizer gain, $\mathrm{Kw}$ decides the value of damping needed by the POD. A washout filter is used to provide the washout signal that ensures the POD output is zero in steady-state. The POD output signal, vPOD is determined based on an anti-windup limiter and a small time constant gives its dynamic. Meanwhile, appropriate phase lead-lag compensation of the input signal is provided by phase compensator blocks.

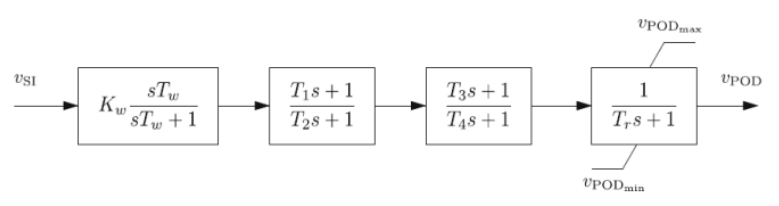

Figure 2. Scheme of the POD controller

\section{FACTS CONTROLLER}

FACTS devices have been known as technologies that were developed to overcome rising problems of power transmission system due to the limit in transmission line construction such as voltage regulation, power flow control and transfer capability enhancement [3]. Recent advances in power electronics allowing FACTS devices to give more options in improving power system stability as they capable in controlling the transmission parameters like series impedance, shunt impedance, phase angle etc. Power system that been installed with FACTS devices will able to increase existing transmission network capacity as well as maintaining or improving the operating margins needed for securing systems stability. Thus, consumers able to consume more power with a minimum effect on the environment at lower cost investment and less time consuming. 
Occurrence of spontaneous oscillation at very low frequencies $(0.2-3.0 \mathrm{~Hz})$ due to development of large interconnection power system has been a problem as it can threaten system security, damages the efficient operation of the power system and affecting small signal stability. Extensive studies have been done in enhancing power system stability as supplementary function of FACTS devices. Recently, researchers have showed interest in developing a design of FACTS devices with POD controller with the aim to enhance the small-signal stability and damp out power oscillation $[6,8,10,11,12]$. FACTS devices are generally divided into two generations $[3,17]$ :

a) First generation of FACTS device where it employs conventional thyristors-switched capacitors and reactors also tap-changing transformers, e.g: Thyristor-Controlled Series Capacitor (TCSC) and Static VAR Compensator (SVC)

b) Second generation of FACTS device where it employs of gate turn-off (GTO) thyristorsswitched as voltage source converters (VSCs), e.g: Static Synchronous Series Capacitor (SSSC), Static Synchronous Compensator (STATCOM) and Unified Power-Flow Controller (UPFC)

\section{PROPOSED BEES ALGORITHM}

Swarm-based optimisation algorithms (SOAs) like Bees Algorithm (BA) have caught the attention of researchers in designing the solution for the controller parameter optimization. The main difference between the soas and direct search algorithm is that soas use a population of solutions for every iteration instead of a single solution [18]. As for BA, several records have shown that the algorithm can produce $100 \%$ rate of success in solving optimisation problem with remarkable robustness and able to converge without being trapped in local minima [18].

Bees algorithm (BA) follows the nature of bees foraging behaviour. The pseudo code in its simplest form is shown in Figure $3[18,19,20,21]$. The BA has a set of numbers of parameters that requires initialization. Those are number of scout bees (n), number of sites selected out of $n$ visited sites (m), number of best sites out of $m$ selected sites (e), number of bees recruited for best e sites (nep), number of bees recruited for the other (m-e) selected sites (nsp), initial size of patches (ngh) which includes site and its neighbourhood and stopping criterion.

As in Figure 3, the algorithm starts with step 1. The scout bees are randomly release in the search space. Then in step 2, the fitness of each visited sites are evaluated. 'Selected bees' are chosen from the highest fitness bees and more bees are sent to their visited sites for neighborhood search. As in step 5 and step 6, the recruited bees are searching near the best 'elite site' and the best bees can directly selected based on the fitness value of their visited sites. In order to get firm solution, detailed search to the neighborhood area can be done by recruiting more bees to the 'elite site'. This differential recruitment is a key operation of the BA. While no restriction in nature, in step 6 however, only the highest fitness bees for each patch will be selected to build the next population. The restriction is done in order to reduce the number of search points. Meanwhile as in step 7, all the other bees are assigned randomly to other search site scouting for new potential solutions. Consequently, the colony will have two parts of solution at the end of every iteration.

1. Initialise population with random solutions.

2. Evaluate fitness of the population.

3. While (stopping criterion not met) //Forming new population.

4. Select sites for neighbourhood search.

5. Recruit bees for selected sites (more bees for best e sites) and evaluate fitnesses.

6. Select the fittest bee from each patch.

7. Assign remaining bees to search randomly and evaluate their fitnesses.

8. End While.

Figure 3. Pseudo code of the basic BA

\section{RESULTS AND DISCUSSION}

As in Figure 4, FACTS-POD controllers are installed in WSCC 3-machine, 9-bus system in order to damp power oscillation. The FACTS devices include the first group of FACTS which are TCSC and SVC, and the second group which are SSSC, STATCOM and UPFC. The parameters of the FACTS-POD controllers are optimized by applying $\mathrm{BA}$ and the eigenvalues results of system each installed with and without FACTS-POD controllers shown in Table 1. The parameters of tuned FACTS-POD controllers are also shown in Table 1 below the eigenvalues columns of each system installed with FACTS-POD.

Through eigenvalues analysis, all the electromechanical eigenvalues of the system installed with FACTS-POD moved further to the left side of splane as compared to the non-controlled system, which is $-0.7075 \pm 11.6065 \mathrm{i}$ and $-0.18646 \pm 7.6324 \mathrm{i}$. For first generation FACTS, both TCSC-POD and SVC-POD show significant improvement where their electromechanical eigenvalues moved far to the left which are $-2.53 \pm 9.827 \mathrm{i},-0.73672 \pm 7.6064 \mathrm{i}$ and $2.7345 \pm 9.3101 \mathrm{i}, \quad-0.66072 \pm 7.5522 \mathrm{i}$ respectively. The electromechanical eigenvalues of system installed with the second genneration FACTS also moved moved significantly to the left as compared to the non-controlled system. System installed with STATCOM-POD showing the most significant improvement in terms of eigenvalues location which is moved to $-2.995 \pm 9.2458 \mathrm{i},-0.71083$ $\pm 7.4782 \mathrm{i}$ while the others eigenvalues are SSSC-POD which moved to $-2.5685 \pm 9.7585 \mathrm{i},-0.72795 \pm 7.4283 \mathrm{i}$ and UPFC-POD which moved to $-2.5131 \pm 9.676 \mathrm{i}$, $0.71722 \pm 7.4804 \mathrm{i}$.

The waveforms of rotor angle and rotor speed after $10 \%$ increased of mechanical input $(\mathrm{Pm})$ of Generator 2 are shown in Table 2 where the waveforms show significant improvement in damping the oscillations. For 
system installed with first generation FACTS, both TCSC-POD and SVC-POD show significant improvement in damping power oscillation. System with both controllers has the rotor angle and rotor speed waveforms damp at 8 seconds and 6 seconds respectively. As for second generation FACTS, system installed with SSSC-POD, UPFC-POD and STATCOM-POD all show significant improvement in damping performance. The waveforms of rotor speed damp at 6 seconds, 7 seconds and 5 seconds respectively while all of the rotor angle waveforms damps at 8 seconds. In addition, the waveform of $\mathrm{Pm}$ of Generator 2 which installed with FACTS-POD controllers also damp out at 8 seconds after being disturbed. These results are consistent with the eigenvalues analysis as the eigenvalues positioned more further to the left, the system is able to stabilized quickly after being disturbed.

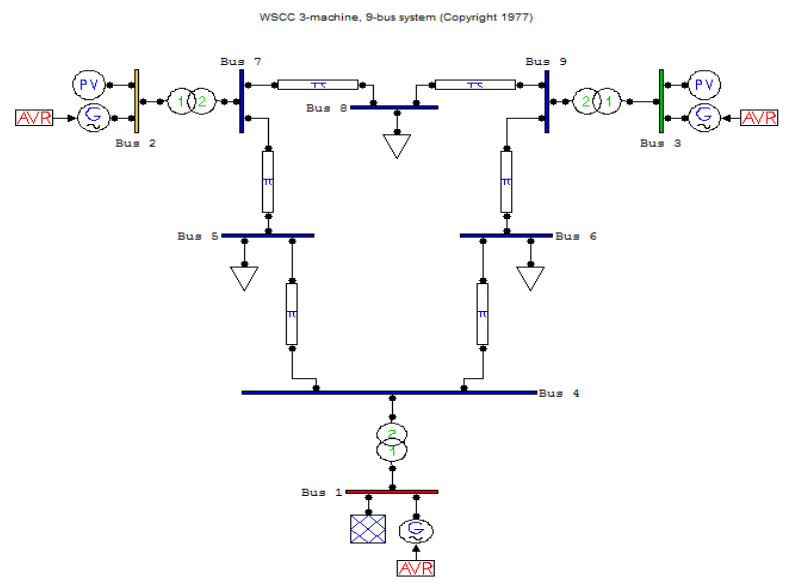

Figure 4. WSCC 3-machine, 9- bus system

Another disturbance done on the system where a 3-phase fault was set to occur at bus-7 from $\mathrm{t}=1.0$ seconds and cleared at $\mathrm{t}=1.1$ seconds. The waveforms of rotor angle, rotor speed, bus voltage and bus angle of bus 7 are shown in Table 2. All waveforms show significant improvement in damping the oscillations after being disturbed as compared to system not installed with any controller. For first generation FACTS, system installed with both TCSC-POD and SVC-POD controllers has the rotor angle oscillations damp at 6 seconds and the rotor speed waveforms damp at 6 seconds and 8 seconds respectively. For second generation FACTS, system installed with SSSC-POD, UPFC-POD and STATCOM-POD all the rotor speed and rotor angle waveforms damps at 6 seconds. In addition, the waveform of bus volatage and bus angle of bus 7 which installed with FACTS-POD controllers also damp out immediately and at 6 seconds, respectively after the 3-phase fault occured . As in case 1, these results are consistent with the eigenvalues analysis as the eigenvalues positioned more further to the left, the system is able to stabilized quickly after being disturbed. This also show that the FACTS-POD controllers are able to overcome the small-signal instability and damp out low frequency oscillations effectively.

\section{CONCLUSION}

The effectiveness of FACTS-POD controllers in enhancing small-signal stability and damping low frequency oscillation has been discussed in this paper. The FACTS devices include are TCSC, SVC, SSSC, STACOM and UPFC. BA is employed to tuned and optimized the parameters of the FACTS-POD controllers with the objective of optimization is to moved the eigenvalues of the system to the left as far as possible. The larger its magnitude in negative, the faster the oscillation will decay and eventually damp out. Then, the controllers has been installed in WSCC 3-machine, 9-bus system and the performance of the controllers has been tested with two cases which are increasing $10 \%$ of mechanical input $(\mathrm{Pm})$ at Generator 2 and the occurrance of 3-phase fault at bus 7 of the system. Each cases will be simulated with each type of FACTS-POD controllers individually and the results will be compared to the system that have not installed with any controller. The

Table 1. Electromechanical eigenvalues of 9bus system and optimized parameters of FACTS-POD controllers

\begin{tabular}{|c|c|c|c|c|c|}
\hline $\begin{array}{l}\text { Without any } \\
\text { controller }\end{array}$ & $\begin{array}{l}\text { With TCSC- } \\
\text { POD }\end{array}$ & $\begin{array}{l}\text { With SVC- } \\
\text { POD }\end{array}$ & $\begin{array}{l}\text { With SSSC- } \\
\text { POD }\end{array}$ & $\begin{array}{l}\text { With UPFC- } \\
\text { POD }\end{array}$ & $\begin{array}{l}\text { With } \\
\text { STATCOM- } \\
\text { POD }\end{array}$ \\
\hline $\begin{array}{l}-0.7075 \\
\pm 11.6065 \mathrm{i} \\
-0.18646 \\
\pm 7.6324 \mathrm{i}\end{array}$ & $\begin{array}{l}-2.53 \\
\pm 9.827 \mathrm{i} \\
-0.73672 \\
\pm 7.6064 \mathrm{i}\end{array}$ & $\begin{array}{l}-2.7345 \\
\pm 9.3101 \mathrm{i} \\
-0.66072 \\
\pm 7.5522 \mathrm{i}\end{array}$ & $\begin{array}{l}-2.5685 \\
\pm 9.7585 \mathrm{i} \\
-0.72795 \\
\pm 7.4283 \mathrm{i}\end{array}$ & $\begin{array}{l}-2.5131 \\
\pm 9.676 \mathrm{i} \\
-0.71722 \\
\pm 7.4804 \mathrm{i}\end{array}$ & $\begin{array}{l}-2.9958 \\
\pm 9.2458 \mathrm{i} \\
-0.71083 \\
\pm 7.4782 \mathrm{i}\end{array}$ \\
\hline $\begin{array}{l}\text { Kw } \\
\text { T1 } \\
\text { T2 } \\
\text { T3 } \\
\text { T4 }\end{array}$ & $\begin{array}{l}-0.1209 \\
0.0540 \\
0.5485 \\
0.0540 \\
0.5485\end{array}$ & $\begin{array}{l}-0.1153 \\
0.8050 \\
0.2753 \\
0.8050 \\
0.2753\end{array}$ & $\begin{array}{c}-86.8711 \\
0.0320 \\
0.4002 \\
0.0320 \\
0.4002\end{array}$ & $\begin{array}{l}-0.8808 \\
0.0694 \\
0.2560 \\
0.0694 \\
0.2560\end{array}$ & $\begin{array}{c}-2.8839 \\
0.05679 \\
0.9680 \\
0.05679 \\
0.9680\end{array}$ \\
\hline
\end{tabular}


Nurul Aziah Arzeha et al. / ELEKTRIKA, XX(X), 20XX, xx-xX

Table 2.Waveforms of system after $10 \%$ increment of mechanical input, Pm of Generator 2

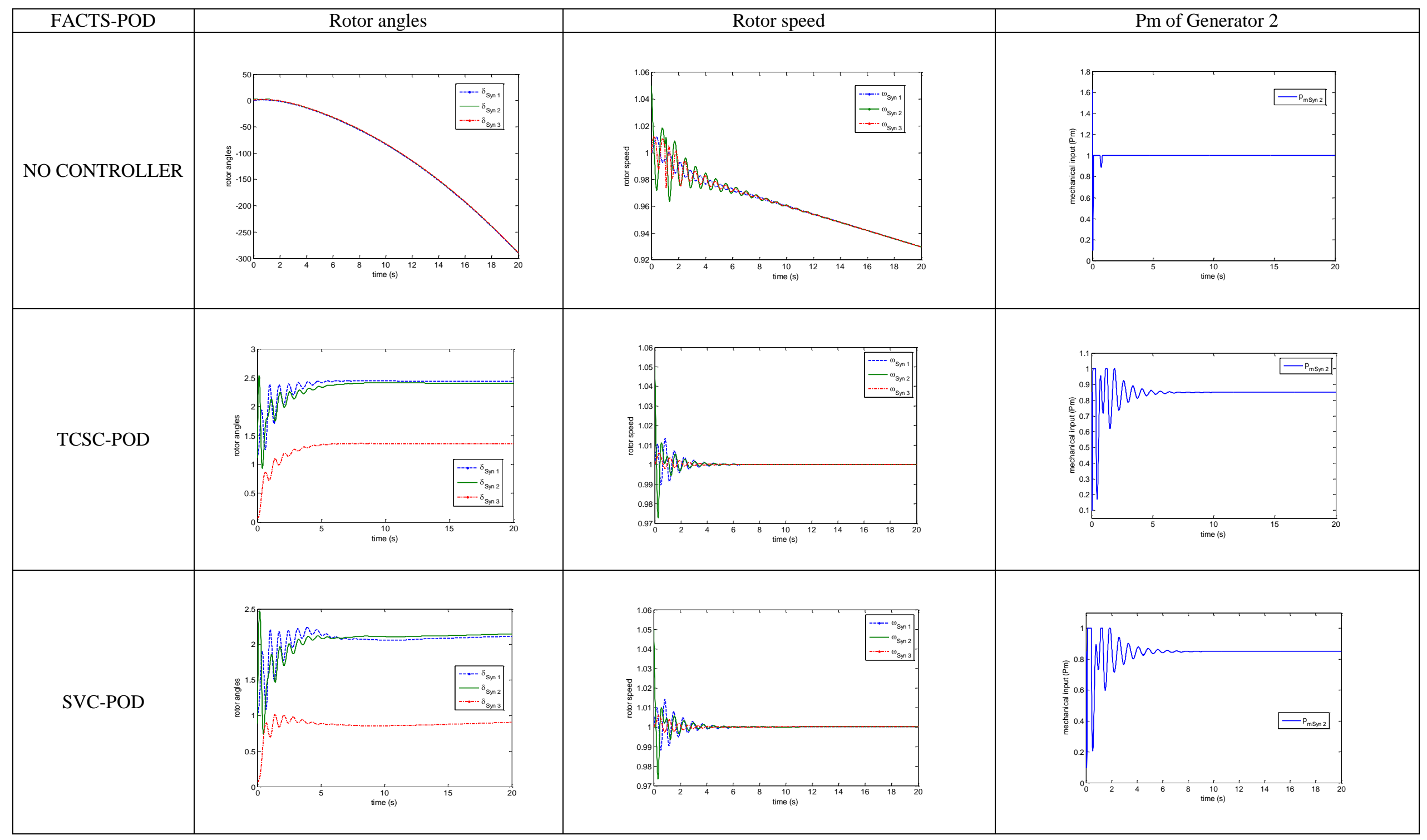


Nurul Aziah Arzeha et al. / ELEKTRIKA, 17(2), 2018, 6-14

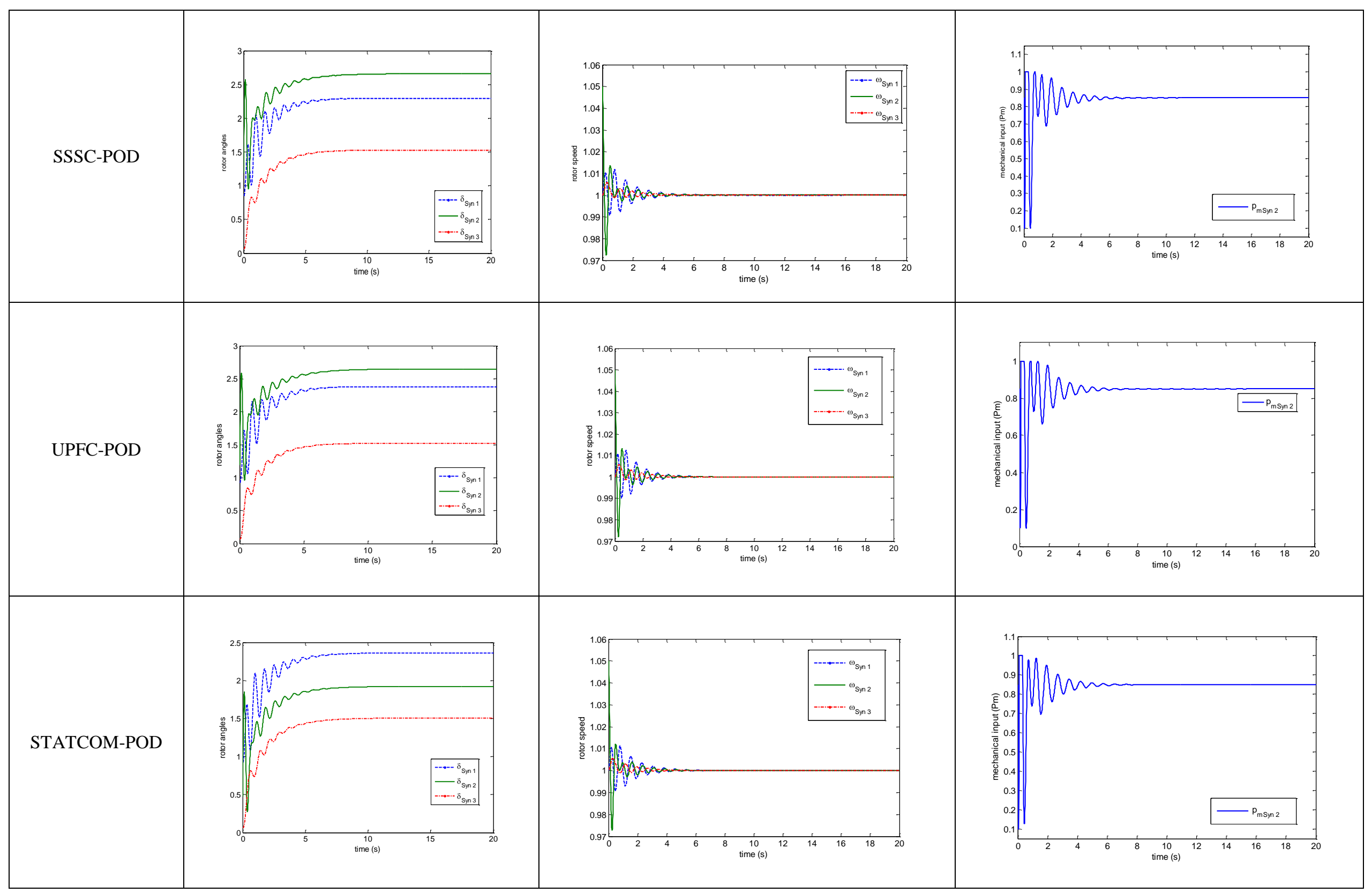


Table 3. Waveforms of system after 3-phase fault at bus 7 at $t=1$ seconds and cleared at $t=1.1$ seconds

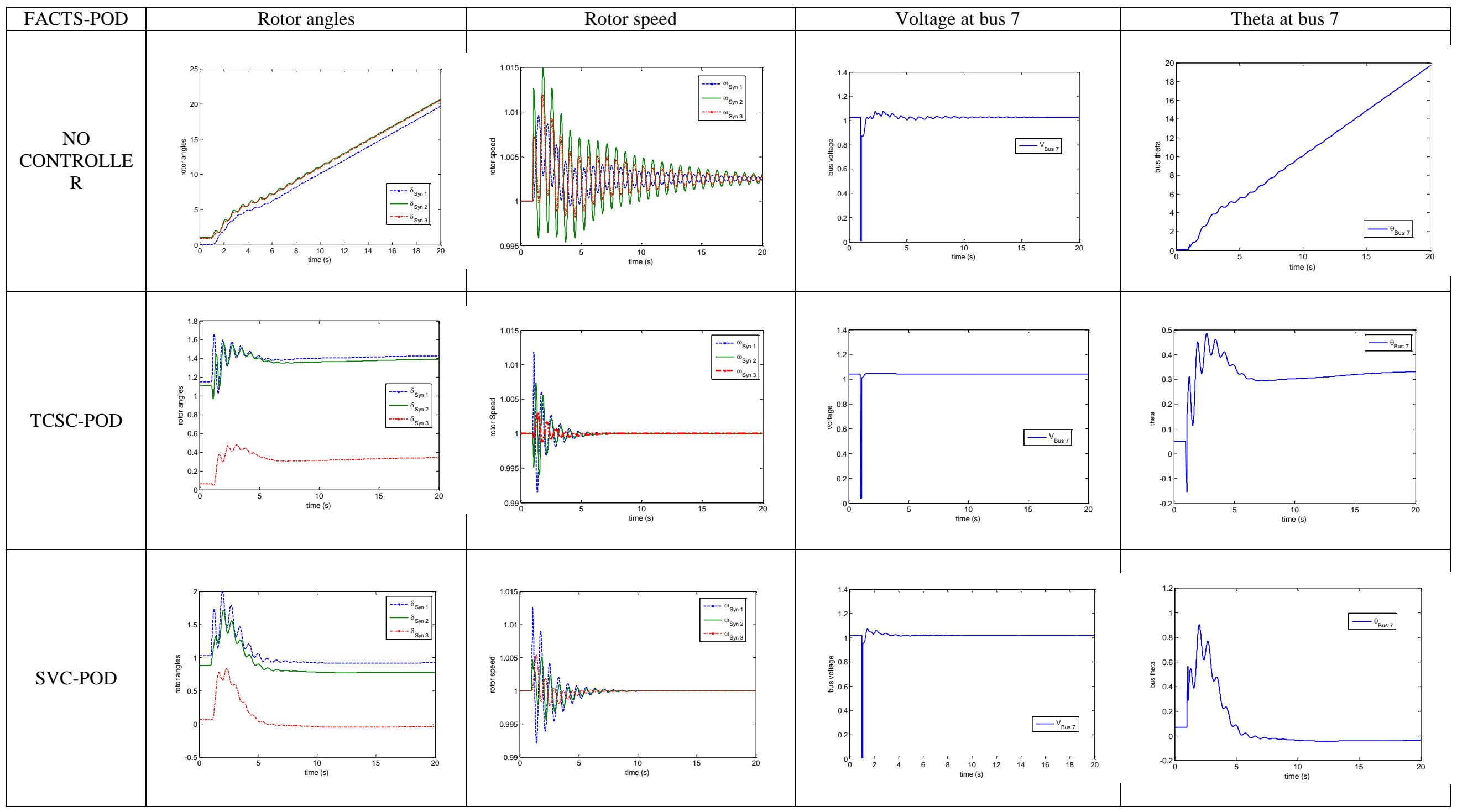


Nurul Aziah Arzeha et al. / ELEKTRIKA, 17(2), 2018, 6-14

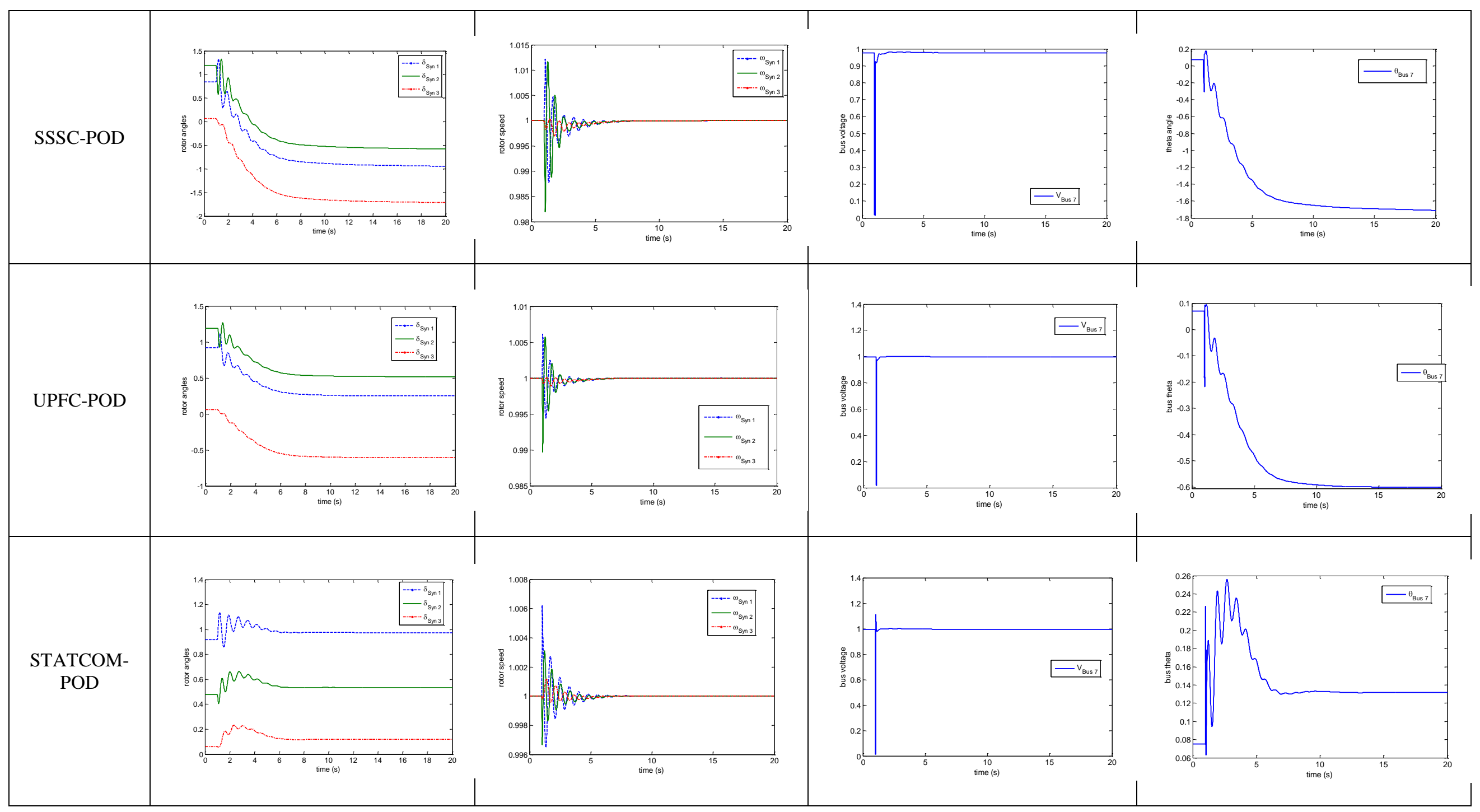


results show significant improvement in terms of eigenvalues position on s-plane and damping out the low frequency oscillation. This proved that FACTS-POD controllers are able to enhance small-signal stability of a system dan damp out low frequency oscillations.

\section{ACKNOWLEDGMENT}

This work was supported by the Fundamental Research Grant Scheme under FRGS/1/2014/TK03/UTM/01/3 through the Ministry of Education, Malaysia.

\section{REFERENCES}

[1] H. Shayeghi, H. A. Shayanfar, S. Jalildazeh and A. Safari, "A PSO based unified power flow controller for damping of power system oscillations," Energy Conversion and Management, vol. 50, pp. 25832592, 2009.

[2] H. Shayeghi, H. A. Shayanfar, S. Jalildazeh and A. Safari, "Tuning of damping controller for UPFC using quantum particle swarm optimizer," Energy Conversion and Management, vol. 51, pp. 22992306, 2010.

[3] M. A. Abido, "Power system stability enhancement using FACTS controllers: A review," The Arabian Journal for Science and Engineering, vol. 34, pp.153-172, 2009.

[4] N. Magaji N and M. W. Mustafa, "Optimal thyristor control series capacitor neuro-controller for damping oscillations," Journal of Computer Science, vol. 5, pp. 980-987, 2009.

[5] N. Magaji and M. W. Mustafa, "Design of power oscillation damping controller for SVC device," 2 nd IEEE International Conference on Power and Energy (PECon 08), Johor Bahru, Malaysia, 1-3 December 2008, pp. 1329 - 1332.

[6] N. Magaji and M. W. Mustafa, "Eigenvalues based method for analysis of power system with SVC device for damping oscillations," in Development of power system dynamic for damping oscillation, A. Khairuddin. Johor, Malaysia: Penerbit Universiti Teknologi Malaysia, 2008, pp. 21-40.

[7] A. Kazemi and M. V. Sohrforouzani, "Power system damping using fuzzy controlled FACTS devices," Electrical Power and Energy Systems, vol. 28, pp. 349-357,2006.

[8] M. Ahmadzadeh, S.S Mortazavi and A. Saeedian, "A novel method of coordinating PSSs and FACTS devices in power system stability enhancement," WSEAS Transaction on Power Systems, vol. 14, pp. 177-188, 2010.

[9] H. Shayeghi, A. Safari and H.A. Shayanfar, "PSS and TCSC damping controller coordinated design using PSO in multi-machine power system," Energy Conversion and Management, vol. 51, pp. 29302937, 2010.

[10] S. Jalildazeh, R. Noroozian, M. R. S. Tirtashi and P. Farhang, "Comparison of TCSC and PSS state feedback controller performances on damping of power system oscillation using PSO," 19th Iranian Conference on Electrical Engineering (ICEE), Tehran, Iran, 17-19 May 2011, pp. 1-5.

[11]A. Ajami and M. Armaghan, "A comparative study in power oscillation damping by STATCOM and
SSSC based on the multiobjective PSO algorithm," Turkish Journal of Electrical Engineering \& Computer Sciences, vol. 21, pp. 213-224, 2013.

[12]H.F. Boroujeni and R. Hemmati, "Dynamic stability enhancement of a multimachine electric power system using STATCOM," Turkish Journal of Electrical Engineering \& Computer Sciences, vol. 2, pp. 1240-1248, 2012.

[13] A. Ajami and R. Gholizadeh, "Optimal design of UPFC-based damping controller using imperialist competitive algorithm," Turkish Journal of Electrical Engineering \& Computer Sciences, vol. 20, pp. 1109-1122, 2012.

[14] N. Magaji and M. W. Mustafa, "Application of SVC device for damping oscillations based on eigenvalue techniques," International Journal of Power, Energy and Artificial Intelligence, vol. 1, pp. 42-49, 2008.

[15]P. Kundur, Power sytem stability and control. McGraw Hill Inc: USA, 1993, pp. 699-722.

[16]H. M. Ayres, I. Kopcak, M. S. Castro, F. Milano and V. F. da Costa, "A didactic procedure for designing power oscillation dampers of FACTS devices," Simulation Modelling Practice and Theory, vol. 18, pp. 896-909, 2010.

[17] G. L. Bodhe, K. Porate and K. L. Thakre, "Voltage stability enhancement of low voltage radial distribution network using static var compensator: A case study, "WSEAS Transactions on Power Systems vol. 4, pp. 32-41, 2009.

[18] D. T. Pham, A. Ghanbarzadeh, E. Koc, S. Otri, S Rahim and M. Zaidi, "The bees algorithm - A novel tool for complex optimisation problems," Intelligent Production Machines and System - 2nd I*PROMS Virtual International Conference, 3-14 July 2006, pp.454-459.

[19]R. Mohamad Idris, A. Khairuddin A and M. W. Mustafa, " Optimal multi-type FACTS allocations in deregulated electricity market using bees algorithm for generation cost reduction," International Journal of Power, Energy and Artificial Intelligence, vol. 1, pp. 60-69, 2009.

[20]R. Mohamad Idris, A. Khairuddin and M. W. Mustafa, "A parallel bees algorithm for ATC enhancement in modern electrical network," Fourth Asia International Conference on Mathematical/Analytical Modelling and Computer Simulation (AMS), Kota Kinabalu, Malaysia, 26-28 May 2010, pp. 450-455.

[21]L. Ozbakir, A. Baykasoglu and P. Tapkan , "Bees algorithm for generalized assignment problem", Applied Mathematics and Computation, vol. 215, pp. 3782-3795, 2010. 